\title{
Effect of an organic residue on herbicide field dissipation
}

\author{
A. Cabrera, L. Cox, P. Velarde \& J. Cornejo \\ Instituto de Recursos Naturales y Agrobiología de Sevilla, \\ CSIC. P.O. Box 1052, 41080 Sevilla, Spain
}

\begin{abstract}
The aim of this work was to study the effect of the application of a solid waste from olive oil production (alperujo) on the movement and persistence of the herbicide diuron [3-(3,4-dichlorophenyl)-1,1-dimethylurea]. The application of alperujo, fresh or composted, to the land has been shown to be an extremely effective contribution to increasing crop yields and to maintaining or improving soil fertility. An experimental olive grove located in Mengibar (Jaen, Spain) was divided into two plots: 1. Plot without organic amendment (blank) and 2. Plot treated with alperujo during 3 years at a rate of $17920 \mathrm{~kg}_{\text {of alperujo ha }} \mathrm{a}^{-1}$. Diuron was applied to both plots at a rate of $2 \mathrm{~kg} \mathrm{ha}^{-1}$ a.i. Triplicates from each plot were sampled at three depths $(0-10,10-20$ and 20-30 cm), air-dried, remains of olive leaves, grass roots, and stones removed and sieved through a $5 \mathrm{~mm}$ mesh sieve. Diuron was extracted with methanol 1:2 weight:volume ratio, the extracts were evaporated to dryness, resuspended in $2 \mathrm{~mL}$ of methanol, filtered and analyzed by HPLC. Higher amounts of diuron were detected at each sampling depth in plots treated with alperujo. The increase in soil organic matter content upon amendment with alperujo slightly increased sorption, suggesting that other factors beside sorption affect diuron degradation rate in organic amended soils.
\end{abstract} Keywords: olive oil production waste, diuron, soil, dissipation, field study.

\section{Introduction}

Soil amendment with olive oil mill wastes increases soil organic matter affecting soil physico-chemical and biological environments and, consequently, affecting immobilization and degradation of herbicides. The increase in soil organic matter can increase sorption potential and reduce pesticide contamination of ground water $[1,2]$. Under controlled laboratory conditions, an increase in 
sorption and a decrease in leaching of simazine was observed in soils amended with alperujo [3-5]. Albarrán et al. [4] also found that in soils enriched with alperujo biodegradation of simazine is reduced, which has been attributed in part to microbial preference to use the exogenous organic matter rather than herbicide. These results suggest that in some cases herbicide persistence can be increased upon organic amendment, and consequently the risk of soil and associated water resources contamination can be increased. However, additional research is needed to investigate the effect of these residues on herbicide fate in soils under field conditions, since these studies are scarce, due to the high cost and difficulty. Barriuso et al. [6] found a reduction in leaching and dissipation rate of atrazine in plots amended with different kinds of sewage sludge. On the contrary, Graber et al. [7] observed a sustained enhanced effect on atrazine and terbuthylazine transport in a field amended with sewage sludge, whereas bromacil was preferentially accumulated in the upper soil layers of the sludge amended soil. Sánchez et al. [8] found no effect of biosolid amendment on methidation mobility.

The aim of the present study was to investigate the effect that soil amendment with alperujo has on immobilization and mobility of the herbicide diuron, and for this purpose a field experiment was performed. Diuron is a substituted urea herbicide used to control a wide variety of annual and perennial weeds and it is relatively persistent in soil with half lives from 1 month to 1 year [9].

\section{Materials and methods}

\subsection{Herbicide, soil and organic wastes}

Diuron (3-3,4-dichlorophenyl-1,1dimethylurea) (purity 99\%), purchased from Dr. Ehrenstorfer GmbH (Augsburg, Germany) is a crystal colorless solid, which has solubility in water of $36.4 \mathrm{mg} \mathrm{L}^{-1}$ at $25^{\circ} \mathrm{C}$ and $\log \mathrm{Kow}\left(25^{\circ} \mathrm{C}\right)$ of $2.85 \pm 0.03$ [10]. The commercial formulation ANIBAL (28.5\% diuron) was purchased from Aragonesas Agro (Madrid, Spain). An organic residue from olive oil production industry (Alperujo, A) was used in this study. Physicochemical properties of A, unamended soil $(\mathrm{S})$ and amended soil $(\mathrm{S}+\mathrm{A})$ are given in Table 1.

Table 1: $\quad$ Physicochemical properties of organic residue alperujo (A) and soil, unamended $(\mathrm{S})$ and amended with $\mathrm{A}(\mathrm{S}+\mathrm{A})$.

\begin{tabular}{|c|c|c|}
\hline Residue/soil & $\mathrm{pH}$ & Organic matter \% \\
\hline $\mathrm{A}$ & 5.81 & 93.2 \\
\hline $\mathrm{S}$ & 8.2 & 1.84 \\
\hline $\mathrm{S}+\mathrm{A}$ & 8.5 & 2.82 \\
\hline
\end{tabular}

\subsection{Sorption studies}

Duplicate samples ( $5 \mathrm{~g})$ of unamended (S) and amended soil $(\mathrm{S}+\mathrm{A})$ were treated with $10 \mathrm{~mL}$ of diuron solutions (initial concentrations, $\mathrm{Ci}$, ranging from 5 to 50 $\mu \mathrm{M}$ in $0.01 \mathrm{M} \mathrm{CaCl}_{2}$ ). Previously, it was determined that equilibrium was 
reached in less than $24 \mathrm{~h}$, and that no measurable degradation occurred during this period. Equilibrium concentrations $(\mathrm{Ce})$ in the supernatants were determined by HPLC under the following conditions: Nova-Pack column, $150 \mathrm{~mm}$ length $\mathrm{x}$ $3.9 \mathrm{~mm}$ i.d.; column packing, $\mathrm{C} 18$; flow rate, $1 \mathrm{~mL} \mathrm{~min}^{-1}$; eluent system for diuron 60:40 water-acetonitrile mixture and UV detection at $250 \mathrm{~nm}$. Sorption isotherms were fitted to Freundlich equation $\left(\mathrm{Cs}=\mathrm{Kf} \times \mathrm{Ce}^{\mathrm{nf}}\right)$ and sorption coefficients $\mathrm{Kf}$ and $\mathrm{nf}$ were calculated.

\subsection{Field study}

Field experiment was carried out in a 50 ha olive grove located in an experimental farm at Mengibar (Jaen, Southern Spain). The climate of the area is typically Mediterranean. The olive trees (62 years old on 2006) were irrigated under drip irrigation from April 15 till October 15 (2006). The total amount of water received was 85441 per olive tree. Total rainfall was $492 \mathrm{~mm}$ in 2006.

Two subplots composed of 4 olive trees (12 x $12 \mathrm{~m}$ plantation distance) were randomly selected from the 50-ha olive grove for the two different treatments: soil amendment with alperujo and herbicide treatment $(\mathrm{S}+\mathrm{A})$ and unamended soil and herbicide treatment (S). Alperujo was applied to $\mathrm{S}+\mathrm{A}$ plots during three consecutive years at the rate of $17.920 \mathrm{~kg} \mathrm{ha}^{-1}$ on the first days of April. After amendment, soil was tilled to a depth of $4 \mathrm{~cm}$. Commercial herbicide formulation ANIBAL was applied with a standard spraying machine to $\mathrm{S}+\mathrm{A}$ and $S$ plots on October 5 (2005) at the rate of $71 \mathrm{ha}^{-1}$. At each subplot, three soil samples were taken with a spade at 0-10, 10-20 and 20-30 cm depth. Samples were extracted twice with methanol at 1:2 soil/solution ratio (recoveries $>90 \%$ for each herbicide). Extracts were mixed and rotary-vacuum evaporated almost to dryness at $40^{\circ} \mathrm{C}$. The residue was dissolved in $2 \mathrm{ml}$ of methanol and analyzed by HPLC as described above.

\subsection{Statistical analysis}

Statistical analysis was carried out using SPSS for Windows v. 14.0 Repeated measures analysis of variance (ANOVA) were used. All pairwise multiple comparisons were performed using the Duncan test. Differences between results were considered statistically significant at $\mathrm{p}<0.05$.

\section{Results and discussion}

\subsection{Sorption studies}

Diuron sorption isotherms were performed and sorption coefficients after fitting sorption isotherms to Freundlich equation are given in Table 2. Sorption studies in the literature have shown that the proportion of organic matter in soil directly influences the amount of diuron adsorbed [11,12]. However, in our study, we find only a slight increase in sorption despite the increase in organic matter from 

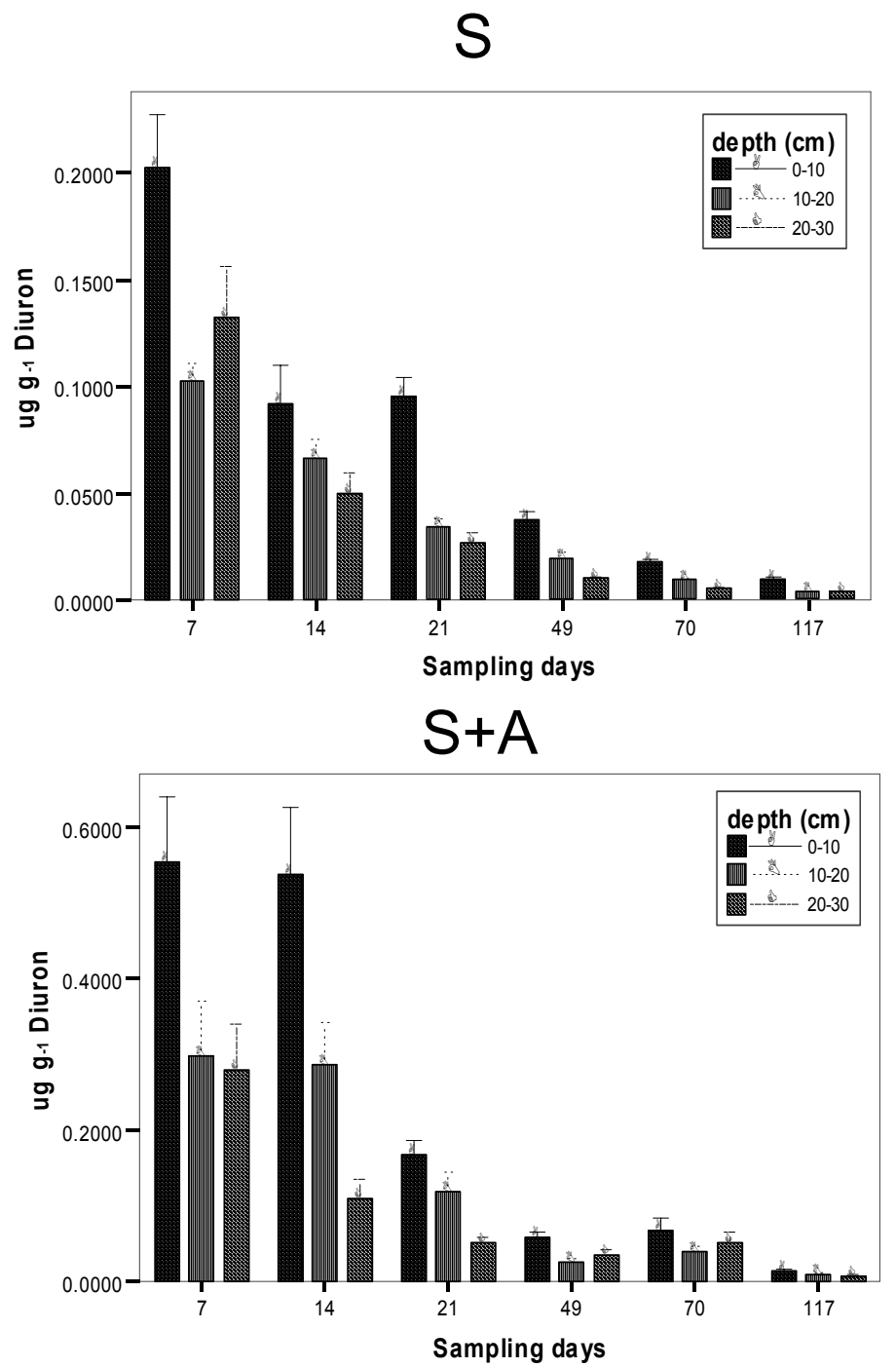

Figure 1: Amounts of diuron recovered at each sampling day at 0-10, 10-20 and $20-30 \mathrm{~cm}$ depth in $\mathrm{S}$ and $\mathrm{S}+\mathrm{A}$ plots.

1.84 to 2.82 (Table 1). In a previous study we have shown alperujo has very high content in dissolved organic matter of very low humification index [13]. This dissolved organic has been shown to be able to interact with the same soil components responsible for diuron sorption [14], which can decrease diuron sorption. Both factors could account for this small increase in sorption. 
Table 2: $\quad$ Diuron sorption coefficients in unamended (S) and amended soils $(\mathrm{S}+\mathrm{A}$ and $\mathrm{S}+\mathrm{CA})$.

\begin{tabular}{|r|c|c|}
\hline Soil & $\mathrm{S}$ & $S+A$ \\
\hline $\mathrm{Kf}$ & $3.45(3.24-3.49)$ & $3.72(3.54-3.88)$ \\
\hline $\mathrm{Nf}$ & $0.80 \pm 0.05$ & $0.83 \pm 0.03$ \\
\hline$R^{2}$ & 0.99 & 1.00 \\
\hline
\end{tabular}

\subsection{Field studies}

The total amounts of diuron recovered from unamended soil (S) and soil treated with alperujo $(\mathrm{S}+\mathrm{A})$ plots are shown in Figure 1. Very low mobility of diuron in depth is observed in every treatment, since, in general, greater amounts of diuron are found within the first $10 \mathrm{~cm}$ of soil profile. There are significant differences between treatments in the total amounts of diuron recovered at each sampling time. Higher amounts of herbicide were detected in S+A plots when compared to $\mathrm{S}$ plots. The small increase in sorption upon amendment suggests that sorption is not the only factor affecting diuron distribution in soil. Differences in degradation rates should also contribute to this. In fact, in previous laboratory dissipation studies, higher half life for diuron was found in a sandy soil treated with alperujo when compared to unamended soil [13]. Also, in the case of the herbicide simazine and a soil amended with alperujo, Albarrán et al. [4] found lower mineralization of this herbicide in amended soils due to a possible toxic effect of alperujo on soil microbial population.

\section{Conclusions}

Addition of organic wastes from olive oil production industry to soil slightly modifies the sorption capacity of soil for diuron but highly increases its persistence in the soil. Other factors such as different degradation rates upon amendment are also involved.

\section{Acknowledgements}

This work has been partially financed by Project AGL 2007-65771 from the Spanish MEC and Research Group RNM 124 of Junta de Andalucia. Alegria Cabrera thanks the MEC for her FPI fellowship.

\section{References}

[1] Barriuso, E., Houot, S. \& Serra-Wittling, C. Influence of compost addition to soil on the behaviour of herbicides. Pestic. Sci. 49, 99. 65-75, 1996.

[2] Cox, L., Celis, R., Hermosín, M. C., Becker, A. \& Cornejo, J. Porosity and herbicide leaching in soils amended with olive-mill wastewater. Agric. Ecosystems and Environ. 65, pp. 151-161, 1997. 
[3] Cox, L., Hermosín, M.C. \& Cornejo, J. Leaching of simazine in organic amended soils. Commun. Soil Sci. Plant Anal. 30, pp. 1697-1706, 1999.

[4] Albarrán, A., Celis, R., Hermosín, M.C., López-Piñeiro, A., Ortega-Calvo, J.J. \& Cornejo, J. Effects of solid olive-mill waste addition to soil on sorption, degradation and leaching of the herbicide simazine. Soil Use Manage. 19, pp. 150-156, 2003.

[5] Albarrán, A. Celis R. Hermosín M.C. López-Piñeiro, A. \& Cornejo, J. Behaviour of simazine in soil amended with the final residue of the oliveoil extraction process. Chemosphere, 54, pp. 717-724, 2004.

[6] Barriuso, E., Calvet, R. \& Houot, S. Field study of the effect of sewage sludge application on atrazine behaviour in soil. Int. J. Environ. Anal. Chem. 59, pp. 107-121, 1995.

[7] Graber, E.R., Dror, I., Bercovich, F.C. \& Rosner, M. Enhanced transport of pesticides in a field trial with treated sewage sludge. Chemosphere 44, pp. 805-811, 2001.

[8] Sánchez, L., Romero, E., Castillo, A. \& Peña, A. Field study of methidation in soil amended with biosolid and a cationic surfactant under different irrigation regimes. Solute transport modelling. Chemosphere 63, pp. 616625, 2006.

[9] Field, J.A., Reed, R.L., Sawyer, T.E., Griffith, S.M. \& Wigington, P.J. Jr. Diuron occurrence and distribution in soil and surface and ground water associated with grass seed production. Journal of Environmental Quality 32, pp. 171-179, 2003.

[10] The e-Pesticide Manual The e-Pesticide Manual. A World Compendium. Tomlin, C.D.S (Ed.) Version 4.0. Fourteenth Edition. BCPC. 2006-07.

[11] Alva, A.K. \& Singh, M. 1990. Sorption of bromacil, diuron, norfluron, and simazine at various horizons in two soils. Bull. Environ. Contam. Toxicol., 45, 365-374.

[12] Gonzalez-Pradas, E., Villafranca-Sanchez, M., Fernandez-Perez, M., Socias-Viciana, M. \& Ureña-Amate, M.D. Sorption and leaching of diuron on natural and peat-amended calcareous soil from Spain. Water Res. 32, pp. 2814-2820, 1998.

[13] Cabrera, A., Cox, L., Velarde, P., Koskinen, W.C. \& Cornejo, J. Fate of diuron and terbuthylazine in soils amended with two-phase olive oil mill waste. J. Agric. Food Chem. 55, pp. 4828-4832.

[14] Cox, L., Velarde, P., Cabrera, A., Hermosín, M.C. \& Cornejo, J. Dissolved organic carbon interactions with sorption and leaching of diuron in organicamended soils. European Journal of Soil Science 58, 714-721, 2007. 